\title{
PENGARUH UKURAN BUTIR SERBUK TULANG PADA PEMBUATAN KOMPOSIT
}

\author{
M. Fajar Sidiq \\ Fakultas Teknik, Program Studi Teknik Mesin \\ Universitas Pancasakti Tegal \\ Email:mr_paimin@yahoo.com \\ Rizal Miftah \\ Fakultas Teknik, Program Studi Teknik Mesin \\ Universitas Pancasakti Tegal
}

\begin{abstract}
ABSTRAK
Penelitian bertujuan untuk mendapatkan hasil yang terbaik terhadap ukuran butir serbuk tulang terhadap sifat mekanik matrial komposit serbuk tulang yang baik pada pengujian kekerasan dan pengujian keausan. Dalam penelitian ini serbuk tulang kambing berfungsi sebagai penguat yang di gabungkan resin epoxy dan diharapkan dapat menciptakan material komposit yang lebih baik. Pada penelitian ini bahan yang digunakan adalah serat serbuk tulang kambing sebagai bahan penguat komposit dan epoxy sebagai bahan matriks. Degan variasi ukuran butir serbuk tulang mesh 40, 60, dan 100 dengan fraksi volume 1:1. Adapun proses pembuatan specimen ini dengan cara penuangan kecetakan dan epoxy yang sudah tercampur dengan serbuk tulang kambing. pembentukan spesimen menyesuaikan dengan kebutuhan pengujian yaitu pengujian keausan dan pengujian kekerasan. Mesin yang digunakan untuk Pengujian kekerasan yaitu 'Brinell tester machine' dengan cara menekan bola ke spesimen dengan beban $30 \mathrm{~kg}$, dan untuk pengujian gesek menggunakan mesin 'riken-ogoshis' proses pengujiannya dengan cara mengesek spesimen dalam waktu 30 detik untuk satu titik. Hasil dari pengujian gesek dan kekerasan yaitu, untuk pengujian keausan tersebut komposit matriks epoxy variasi ukuran mesh 100 memiliki nilai ketahanan keausan sebesar $9,59 \times 10^{-8} \mathrm{~mm}^{2} / \mathrm{kg}$. Untuk pengujian kekerasan tersebut komposit matriks epoxy variasi ukuran mesh 100 mempunyai nilai tertinggi yaitu 25,82 BHN.
\end{abstract}

Kata kunci: metalurgi serbuk, serbuk tulang, komposit serbuk.

\begin{abstract}
The study aims to get the best result against bone powder grain size on mechanical properties of bone powder composite matrial good on hardness testing and wear testing. In this study, bone powder goat serves as reinforcement in combination of epoxy resins and is expected to create composite materials that are good. In this study, the materials used are fiber goat bone powder as a reinforcing material composite and epoxy as a matrix material. With the variation of bone powder grain size mesh 40, 60, and 100 with the volume fraction of 1: 1. The process of making these specimens by way of pouring into molds and epoxy powder that was mixed with goat bones. establishment specimen suit the needs of testing is test the wear and hardness testing. Machines used for hardness testing of 'Brinell tester machine' by tapping the ball into the specimen with a load of $30 \mathrm{~kg}$, and for friction testing using the machine 'RIKEN-ogoshis' testing process by way of rubbing the specimen within 30 seconds to a single point. The results of the testing of friction and violence which, for testing the wear of epoxy matrix composite 100 has a mesh size variation value of the wear resistance of $9.59 \times 10^{-8} \mathrm{~mm}^{2} / \mathrm{kg}$. For testing the hardness variations epoxy matrix composite mesh size of 100 has the highest score is $25.82 \mathrm{BHN}$
\end{abstract}

Keywords: powder metallurgy, bone powder, the composite powder.

\section{PENDAHULUAN}

\subsection{Latar Belakang}

Komposit matrik polimer konvensional sering disebut filled polymers, dewasa ini merupakan material yang sangat dibutuhkan secara konvensional dalam aplikasi industry. Sebagai contoh talck filled polypropylene untuk aplikasi otomotif, mineral filled epoxies untuk aplikasi elektronik yang semuanya berdasar pada penguatan berskala mikro. 
Dalam perkembangan teknologi komposit mengalami kemajuan yang sangat pesat ini dikarenakan keistimewaan sifat yang renewable atau terbarukan dan juga rasio kekuatan terhadap berat yang tinggi kekakuan, ketahan terhadap korosi dan lain-lain, sehingga mengurangi konsumsi bahan kimia maupun gangguan lingkungan hidup.kemudian dikenal dengan tipe cetak. Pada penelitian ini peneliti memakai penguat serbuk tulang kambing dengan variasi butir serbuk mesh 40, 60, dan 100. Untuk komposit menggunakan epoksi dengan perbandingan 1:1.

\subsection{Klasifikasi Komposit}

Komposit adalah suatu material yang terbentuk dari dua atau lebih material pembentuknya melalui pencampuran yang tidak homogen, dimana sifat mekanik dari material pembentuknya berbeda-beda. Dikarenakan karakteristik pembentuknya berbeda-beda, maka akan menghasilkan material baru yaitu komposit yang mempunyai sifat mekanik dan karakteristik yang berbeda dari material- material pembentuknya ( Smallman, 2007).

Epoxy atau polyepoxide adalah sebuah polimer epoxide thermosetting yang bertambah bagus bila dicampur dengan sebuah agen katalis atas "pengeras" (Wikipedia, 2014). Epoxy ini terdiri dari monomer atau polimer rantai pendek dengan kelompok epoxida di kedua ujung. epoxy resin biasanya memerlukan campuran yang tepat dari dua komponen yang membentuk kimia ketiga.

Tergantung pada sifat yang diperlukan, rasio mungkin dari 1:1 atau lebih dari 10:1. Aplikasi untuk bahan epoxy berbasis luas dan mencakup pelapis, perekat dan material komposit. Epoxy digunakan sebagai bahan matriks struktur yang kemudian diperkuat dengan serat. Serat yang biasa digunakan secara umum antara lain serat kaca, serat karbon, kevlar dan boron. Epoxy juga digunakan sebagai bahan perekat struktural seperti kayu dan lainnya.

\subsection{Fraksi Volume}

Jumlah kandungan serat dalam komposit, merupakan hal yang menjadi perhatian khusus pada komposit berpenguat serat. Untuk memperoleh komposit berkekuatan tinggi, distribusi serat dengan matrik harus merata pada proses pencampuran agar mengurangi timbulnya void. Untuk menghitung fraksi volume, parameter yang harus diketahui adalah berat jenis resin, berat jenis serat, berat komposit dan berat serat. Adapun fraksi volume yang ditentukan dengan persamaan :

$$
\begin{aligned}
& W f=\frac{w f}{w c}=\frac{\rho f v f}{\rho c v f}=\frac{\rho f}{\rho c} V f \\
& V f=\frac{\rho c}{\rho f} W f=1-V m .
\end{aligned}
$$

Jika selama pembuatan komposit diketahui massa fiber dan matrik, serta density fiber dan matrik, maka fraksi volume dan fraksi massa fiber dapat dihitung dengan persamaan :

$$
V f=\frac{w f / \rho f}{w f / \rho f+w m / \rho m}
$$

Dimana :

$\begin{array}{lll}\mathrm{W} f: \text { fraksi berat serbuk } & \mathrm{w} f & : \text { berat serbuk } \\ \mathrm{wc}: \text { berat komposit } & \rho f & : \text { density serbuk } \\ \rho \mathrm{c}: \text { density komposit } & \mathrm{V} f & : \text { fraksi volume serbuk } \\ \mathrm{Vm}: \text { fraksi volume matrik } & \mathrm{v} f & : \text { volume serbuk }\end{array}$

vm : volume matrik

\subsection{Karakteristik Serbuk}

Dalam teknik metalurgi serbuk semua proses diawali dengan pembuatan serbuk, oleh sebab itu kita harus memahami sifat-sifat dan karakteristik dari serbuk tersebut. Umumnya serbuk mempunyai ukuran yang lebih besar dari asap dan lebih kecil dari pasir ( German, 1994 ). Sifat-sifat spesifik dari serbuk logam ini tergantung bagaimana serbuk ini diproduksi. Serbuk yang dihasilkan dengan pendinginan cepat mempunyai struktur yang berbeda dengan material yang didinginkan dibawah kondisi seimbang.

Serbuk ini dapat terdiri dari fasa baru ( termasuk struktur amorph) dengan banyak skala yang lebih kecil dari mikro struktur, tidak ada komposisi yang seimbang dan mengurangi segregasi. Struktur 
amorphous terjadi pada temparatur kamar karena panas yang diekstraksikanlebih cepat daripada pembekuan yang terjadi, dan berlangsung sekali pendinginan karena angka difusi yang rendah. Atomatom berdifusi untuk mengatur menjadi kristal, pengaturan atom secara acak yang terjadi pada fasa liquidus. (ASM, Powder Metallurgy Committee).

\section{METODE PENELITIAN}

\subsection{Sampel}

Sampel dibuat dengan menggunakan teknologi hand lay-up, yaitu dengan membuat lapisan epoxy dengan serbuk tulang kambing kemudian diberi tekanan, setelah sebelumnya serbuk tulang kambing diukur volume sesuai dengan komposisi yang diinginkan. Untuk ukuran sampel akan dibuat sesuai pengujian kekerasan, ukuran sampel yang akan dibuat mengacu pada standar ASTM E10 (Standard Test Method for Tensile Properties of Plastics) dengan spesifikasi bentuk.

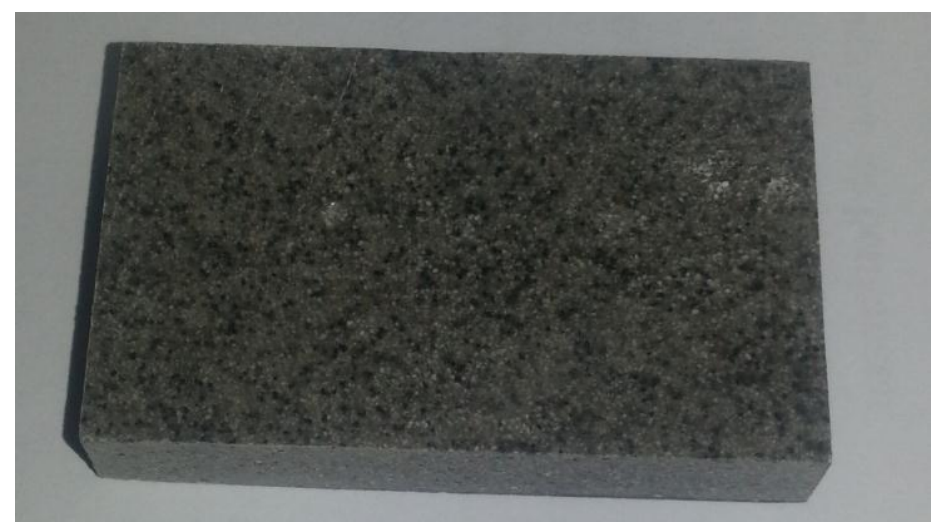

Gambar 1. Spesimen uji kekerasan

Sedangkan untuk sampel pengujian keausan akan mengacu pada metode uji keausan Ogoshi, dengan bentuk sampel dan dimensi seperti Gambar 2 berikut ini

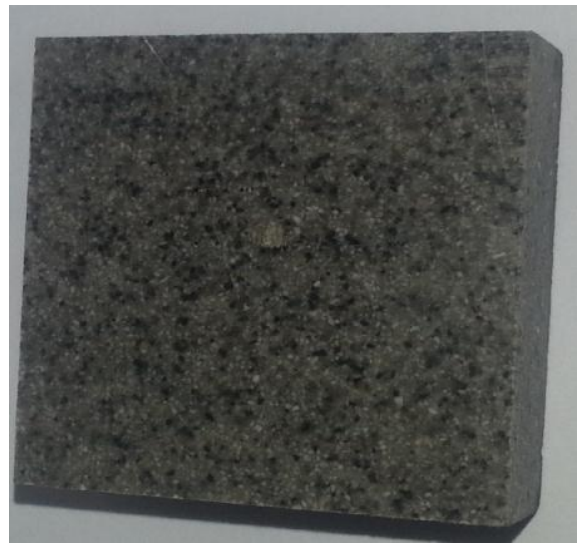

Gambar 2. Spesimen uji keausan

\subsection{Alat}

Alat-alat yang digunakan dalam penelitian ini antara lain :

a. Gelas Ukur

Gelas Ukur digunakan untuk mengukur volume epoxy, hardener dan serbuk yang dicampurkan sesuai dengan fraksi volumenya.

b. Cetakan

Cetakan terbuat dari plat besi berbentuk persegi dengan sisinya $15 \mathrm{~cm}$ dan tingginya $1,1 \mathrm{~cm}$.

c. Waterpass

Untuk memastikan specimen yang dicetak tidakmiring.

d. Jangka Sorong

Jangka sorong digunakan untuk mengukur panjang, lebar dan tebal spesimen. 
e. Mesin Potong

Mesin potong digunakan untuk memotong hasil komposit untuk dibentuk menjadi spesimen uji yang telah ditentukan standar ukurannya.

f. Lesung dan Alu

Alat untuk menghancurkan tulang agar jadi serbuk.

g. Oven

Oven digunakan untuk mengeringkan tulang sebelum dibikin serbuk..

h. Alat Uji Sifat Mekanik

Alat uji yang digunakan untuk mengetahui sifat mekanik komposit.

i. Mesh (Ayakan)

Alat ini digunakan untuk menyaring serbuk tulang kambing

\subsection{Teknik Pengambilan Sampel}

Tahapan-tahapan pengambilan data sampel :

a. Pemilihan Spesimen

Pemilihan specimen dilakukan menurut standar mesin uji, dengan jumlah specimen dilakukan secara random dan berjumlah ganjil.

b. Tahap proses persiapan serbuk tulang kambing

Pada tahap ini dilakukan perlakuan terhadap serbuk tulang kambing, dimana tahap pertama yaitu proses pengumpulan tulang kambing yang kemudian dikeringkan dengan cara dioven dan dihancurkan untuk dijadikan serbuk.

c. Tahap Mesh (Ayakan)

Setelah melalui tahap pertama yaitu proses persiapan serbuk tulang kambing tahap berikutnya adalah mesh atau pengayakan.tahap ini serbuk tulang yang sudah digiling akan diayak melalui proses ayakan mesh 40, 60, dan kemudian 100. Serbuk yang masih besar akan digiling kembali secara perlahan kemudian diayak lagi.

d. Tahap pembuatan material komposit

Pada proses pembuatan spesimen, sampel diukur sesuai fraksi volume dengan perbandingan volume antara epoxy : hardener : serbuk tulang mesh 40 adalah 1:1:1. Begitu juga untuk fraksi volume yang lainya. Masukan epoxy dan hardener terlebih dahulu kedalam wadah, aduk sampai merata setelah itu campurkan serbuk tulang kemudian aduk lagi sampai merata.. kemudian dituang secara perlahan ke dalam cetakan yang dan dibiarkan sampai beberapa menit (5 menit) untuk menghilangkan gelembung udara yang terperangkap di dalamnya. Kemudian panaskan dibawah sinar matahari dengan menggunakan waterpass pastikan permukaanya rata.

e. Tahap karakterisasi

Tahap ini merupakan tahap terakhir, dimana komposit telah diperoleh dan dilakukan analisa karakterisasi. Tahap ini merupakan tahap untuk menganalisa karakterisasi komposit dari serbuk tulang kambing dengan uji keausan dan uji kekerasan.

\subsection{Pengujian Sifat Mekanik}

a. Uji Keausan Komposit

Pengujian ini bertujuan untuk mendapatkan sifat mekanik komposit dalam ketahanan terhadap keausan.

1) Bahan yang diuji adalah Komposit epoksi

2) Standar pengujian menggunakan Metode Ogoshi

3) Mesin pengujian Riken Ogoshi Testing Machine

4) Tempat Lab. FT UGM Yogyakarta

Uji keausan dilakukan terhadap sampel yang terdiri dari bahan utama matriks epoksi dan pencampuran bahan penguat serbuk tulang kambing dengan fraksi volume 1:1 dan variasi ukuran butir serbuk tulang mesh 40, 60, dan 100. Pengujian mengacu pada standar metode Ogoshi (Ogoshi High Speed Universal Wear Testing Machine) dengan kondisi pengujian 12,72 kg dan jarak abrasi $400 \mathrm{~m}$ dan kecepatan putaran dari motor 0,250 rpm dalam waktu 30 detik akan memperoleh alur bekas abrasi. 


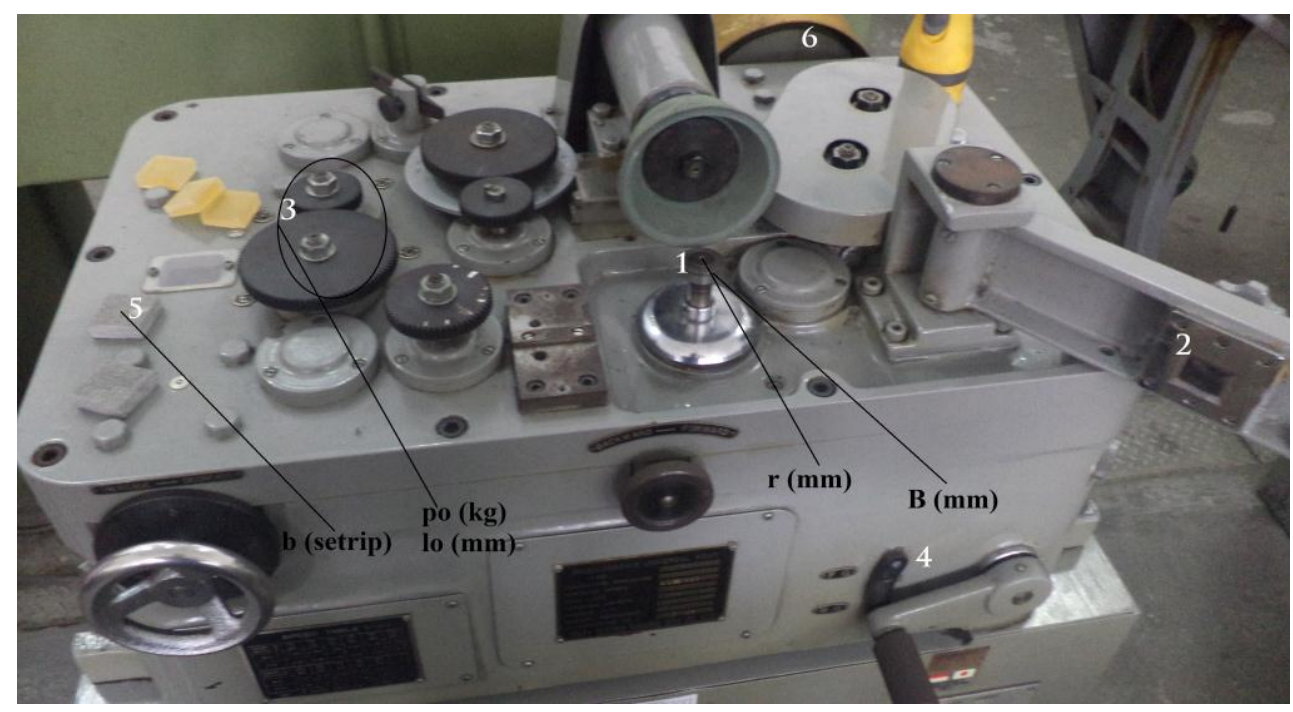

Gambar 3. Mesin UJi Ogoshi

( Sumber : TOKYO TESTING MACHINE MFG. CO.,LTD )

b. Uji Kekerasan Komposit

Pengujian ini bertujuan untuk mendapatkan nilai kekerasan komposit pada beban tertentu.

1) Bahan yang diuji Komposit epoksi

2) Standar pengujian ASTM E10

3) Mesin penguji Brinell Testing Machine

4) Tempat Lab. FT UGM Yogyakarta

Uji kekerasan dilakukan terhadap sampel yang terdiri dari bahan utama matriks epoksi dan pencampuran bahan penguat serbuk tulang kambing dengan fraksi volume 1:1 dan variasi ukuran butir serbuk tulang mesh 40,60, dan 100. Pengujian mengacu pada standar ASTM E10 dengan kondisi pengujian beban uji yang diberikan $30 \mathrm{~kg}$ dan diameter indentor $2,5 \mathrm{~mm}$ waktu 10 detik dengan pembesaran lensa $50 \mathrm{x}=19$ setrip disetiap $\mathrm{mm}$.

\section{HASIL DAN PEMBAHASAN}

\subsection{Pengujian Keausan}

Uji keausan dilakukan dengan metode Ogosh diambil rata-rata ketahanan keausanya dengan 12 spesimen. Data-daa dari pengujian dimasukan ketabel dan dihitung nilai keausanya. Seperti pada specimen ukuran serbuk mesh 40 :

$B=3 \mathrm{~mm}, b^{\mathrm{a}}=122,3$ setrip, $r=13,5 \mathrm{~mm}$, po $=12,72 \mathrm{~kg}, \mathrm{lo}=400 \mathrm{~m}=400.000 \mathrm{~mm}$

$$
\begin{aligned}
W s & =\frac{3.122,3}{8.13,5 \cdot 12,72.400000} \\
W s & =\frac{366,9}{549504000} \\
& =0,00000673
\end{aligned}
$$

Diketahui hasil specimen yang lain dapat dilihat pada Tabel 1. 
Tabel 1. Data Yang Diperoleh Dan Hasil Perhitungan Keausan

\begin{tabular}{|c|c|c|c|c|c|c|c|c|}
\hline $\begin{array}{c}\text { Komposisi } \\
\text { bahan }\end{array}$ & $\begin{array}{c}b \\
\text { (setrip) }\end{array}$ & $b^{3}$ & $\begin{array}{c}d \\
(\mathrm{~mm})\end{array}$ & $\begin{array}{c}r \\
(m m)\end{array}$ & $\begin{array}{c}B \\
(\mathrm{~mm})\end{array}$ & $\begin{array}{l}\text { Jarak } \\
\text { abrasi } \\
\text { lo (mm) }\end{array}$ & $\begin{array}{l}\text { Po } \\
\text { (kg) }\end{array}$ & $\begin{array}{c}\text { Hasil abraksi } \\
W s=\frac{\text { B.b3 }}{\text { 8.r.Po.lo }} \\
\left(\mathrm{mm}^{2} / \mathrm{kg}\right)\end{array}$ \\
\hline \multirow{3}{*}{$\begin{array}{l}\text { Tanpa } \\
\text { serbuk }\end{array}$} & 15 & 55,3 & 27 & 13,5 & 3 & 400.000 & 12,72 & 0,000000302 \\
\hline & 21,3 & & 27 & 13,5 & 3 & 400.000 & 12,72 & \\
\hline & 19 & & 27 & 13,5 & 3 & 400.000 & 12,72 & \\
\hline Rata Rata & 18,4 & & & & & & & \\
\hline \multirow{3}{*}{$\begin{array}{c}\text { Serbuk } \\
\text { mesh } 40\end{array}$} & 39,3 & 122,3 & 27 & 13,5 & 3 & 400.000 & 12,72 & 0,000000673 \\
\hline & 39 & & 27 & 13,5 & 3 & 400.000 & 12,72 & \\
\hline & 44 & & 27 & 13,5 & 3 & 400.000 & 12,72 & \\
\hline Rata Rata & 40.7 & & & & & & & \\
\hline \multirow{3}{*}{$\begin{array}{c}\text { Serbuk } \\
\text { mesh } 60\end{array}$} & 49,7 & 150,7 & 27 & 13,5 & 3 & 400.000 & 12,72 & 0,000000822 \\
\hline & 51,7 & & 27 & 13,5 & 3 & 400.000 & 12,72 & \\
\hline & 49,3 & & 27 & 13,5 & 3 & 400.000 & 12,72 & \\
\hline Rata Rata & 50,2 & & & & & & & \\
\hline \multirow{3}{*}{$\begin{array}{c}\text { Serbuk } \\
\text { mesh } 100\end{array}$} & 57.3 & 175,7 & 27 & 13,5 & 3 & 400.000 & 12,72 & 0,000000959 \\
\hline & 54,7 & & 27 & 13,5 & 3 & 400.000 & 12,72 & \\
\hline & 63,7 & & 27 & 13,5 & 3 & 400.000 & 12,72 & \\
\hline Rata rata & 58.6 & & & & & & & \\
\hline
\end{tabular}

\subsection{Pengujian Kekerasan}

Uji kekerasan dilakukan dengan 2 titk dengan jumlah specimen 12 buah. Data dari pengujian dimasukan ketabel dan dihitung nilai kekerasanya.

Table 2. Hasil Pengujian Kekerasan Bahan

\begin{tabular}{lcccc}
\hline Komposisi bahan & Specimen 1 & Specimen 2 & Specimen 3 & Rata-rata \\
\hline Tanpa serbuk & 26 & 27 & 26 & 26,3 \\
Serbuk mesh 40 & 26 & 27 & 26 & \\
& 25 & 24,5 & 24 & 24,6 \\
Serbuk mesh 60 & 25 & 24,5 & 24,5 & 23,25 \\
& 24,5 & 23 & 23 & 22,5 \\
Serbuk mesh 100 & 24 & 23 & 22 & \\
& 22,5 & 23 & 22,5 & 22 \\
\hline
\end{tabular}
40 :

Dari table diatas dapat dicari nilai keausanya, Dihitung nilai ketahanan pada specimen serbuk mesh $\mathrm{D}: 2,5 \mathrm{~mm}, \pi: 3,14, \mathrm{P}: 30 \mathrm{~kg}, \mathrm{~d}: 1,29 \mathrm{~mm}$, maka :

$$
\begin{aligned}
& \mathrm{BHN}=\frac{2.30}{3,14,2,5\left(2,5-\sqrt{\left.2,5^{2}-1,29^{2}\right)}\right.} \\
& \mathrm{BHN}=\frac{60}{7,85(2,5-\sqrt{6,25-1,66)}} \\
& \mathrm{BHN}=21,35
\end{aligned}
$$


Tabel 3. Perhitungan Nilai Uji Kekerasan

\begin{tabular}{ccccccc}
\hline Komposisi bahan & $\boldsymbol{d}=\frac{\text { rata }- \text { rata }}{\mathbf{1 9}}$ & $\begin{array}{c}\mathbf{D} \\
(\mathbf{m m})\end{array}$ & $\boldsymbol{\pi}$ & $\mathbf{P}(\mathbf{k g})$ & $\mathbf{B H N}=\frac{2 \mathrm{p}}{\boldsymbol{\pi D}\left(\mathrm{D}-\sqrt{\left.D^{2}-d^{2}\right)}\right.}$ \\
\hline Tanpa serbuk & 1,38 & 2,5 & 3,14 & 30 & 18,376 \\
Serbuk mesh 40 & 1,29 & 2,5 & 3,14 & 30 & 21,35 \\
Serbuk mesh 60 & 1,22 & 2,5 & 3,4 & 30 & 24,04 \\
Serbuk mesh 100 & 1,18 & 2,5 & 3,14 & 30 & 25,82 \\
\hline
\end{tabular}

\subsection{Pembahasan Uji Keausan}

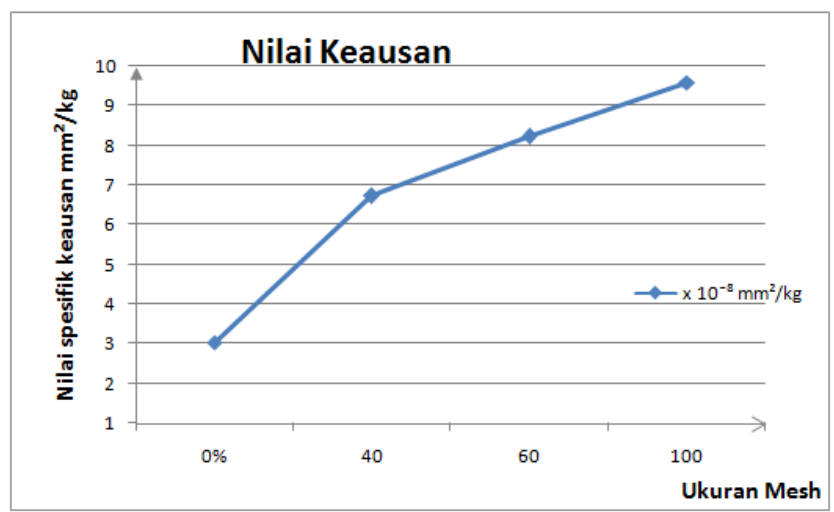

Gambar 4. Pengaruh Ukuran Serbuk (Mesh) Terhadap Nilai Keausan

Dari Grafik yang ditunjukkan pada gambar 4, terlihat bahwa dengan tanpa campuran serbuk tulang menunjukan nilai keausan sebesar $3,02 \times 10^{-8} \mathrm{~mm}^{2} / \mathrm{kg}$. Pada campuran serbuk mesh 40 dengan volume epoxy : hardener : serbuk adalah 1:1:1 menunjukan nilai keausan sebesar $6,73 \times 10^{-8} \mathrm{~mm}^{2} / \mathrm{kg}$. Begitu juga pada campuran serbuk mesh 60 dan mesh 100 menunjukan nilai keausan sebesar $8,22 \times 10^{-8} \mathrm{~mm}^{2} / \mathrm{kg}$ dan $9,59 \times 10^{-8} \mathrm{~mm}^{2} / \mathrm{kg}$.

\subsection{Pembahasan Uji Kekerasan}

Dari Grafik yang ditunjukkan pada gambar 5 terlihat bahwa tanpa campuran serbuk tulang menunjukan nilai kekerasan sebesar 18,376 BHN. Pada campuran serbuk mesh 40 dengan volume epoxy : hardener : serbuk adalah 1:1:1 menunjukan nilai kekerasan sebesar 21,35 BHN. Begitu juga pada campuran serbuk mesh 60 dan mesh 100 menunjukan nilai kekerasan sebesar 24,04 BHN dan 25,82 BHN.

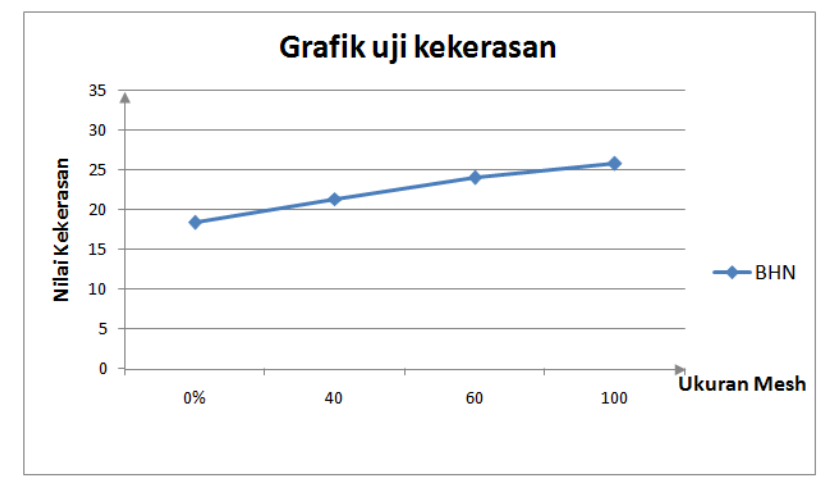

Gambar 5. Pengaruh Ukuran Serbuk (Mesh) Terhadap Nilai Kekerasan

\section{KESIMPULAN}

Berdasarkan dari hasil pengujian keausan dan pengujian kekerasan yang telah dilakukan pada bahan komposit resin epoxy dengan penguat serbuk tulang kambing dengan variasi ukuran butir serbuk mesh 40 , 60, dan 100. maka dapat disimpulkan sebagai berikut : Ukuran butir serbuk Mesh 100 mpunyai nilai yang paling tinggi terhadap uji keausan sebesar $9,59 \times 10^{-8} \mathrm{~mm}^{2} / \mathrm{kg}$, sedangkan pada variasi ukuran mesh 40 
dan 60 adalah $6,73 \times 10^{-8} \mathrm{~mm}^{2} / \mathrm{kg}$ dan $8,22 \times 10^{-8} \mathrm{~mm}^{2} / \mathrm{kg}$. dan untuk uji kekerasan ukuran butir serbuk mesh 100 mempunyai nilai sebesar 25,82 BHN, sedangkan pada variasi ukuran mesh 40 dan 60 berturut turut adalah 21,35 BHN dan 24,04 BHN. faktor ukuran butir serbuk mempengaruhi melekatnya serbuk dan epoxy sebagai penguat dan juga mempengaruhi nilai yang dihasilkan. disamping itu serbuk yang tidak merata di dalam komposit menyebabkan penumpukan serbuk pada titik - titik tertentu yang mengakibatkan serbuk kurang mampu menahan beban yang diberikan.

\section{DAFTAR PUSTAKA.}

[1] Callister, W. D., 2007, “Materials Science and Engineering”, John Wiley \& Sons, Inc., 7nd edition, New York.

[2] Dieter, G.E., 1987, "Metalurgi Mekanik”, terj. Sriati D., Erlangga, Jakarta, hal. 6.

[3] Fajar Sidiq dkk, M., 2015, "Pengaruh Sudut Nozel Terhadap Hasil Serbuk Logam Dengan Metode Atomisasi", Jurnal engineering vol. 10 No. 1

[4] Fajar Sidiq, M., 2015, "Variasi Tekanan Pada Proses Metalurgi Serbuk Dengan Metode Atomisasi Air", Proceeding Seminar Nasional Inovasi dan Rekayasa Teknologi ke-4 (SNIRT-IV) UNTAG Cirebon

[5] German, R.M., 1994, "Powder Metallurgy Science”, Metal Powder Industries Federation, New Jersey.

[6] Gibson, R.F. 1994, "Principles of Composites Material Mechanics.”, Singapore Mc. Graw Hill.

[7] Jones, R.M., 1975, "Mechanis Of Composite Materials", Hemisphere Publishing Co.,New York.

[8] Pratama., 2011, "Analisa Sifat Mekanik Komposit Bahan Kampas Rem Dengan Penguat Fly Ash Batubara”, Jurusan Mesin Fakultas Teknik, Universitas Hasanuddin Makasar.

[9] Prisma Frendi Wardana dan Yuyun E.S.,2013, "Pemanfaatan Serbuk Bambu sebagai Alternatif Material Kampas Rem Non-Asbestos Sepeda Motor”, Jurnal Teknik Mesin. Universitas Sebelas Maret. Surakarta

[10] Setiyanto, 2009. "Pengaruh Variasi Temperatur Sintering Terhadap Ketahanan Bahan Rem Gesek Sepatu”, Tugas Akhir S-1, Fakultas Teknik Mesin Universitas Muhammadiyah Surakarta, Surakarta.

[11] Smallman, R.E. dan Bishop, R.J.2007. "Metalurgi FisikModern dan Rekayasa Material, Erlangga, Jakarta.

[12] Sutikno Nathan Hindarto dkk., 2009, "Pembuatan Bahan Gesek Kampas Rem Menggunakan Serbuk Tempurung Kelapa Sebagai Pemodifikasi Gesek", Jurnal Fakultas Matematika dan Ilmu Pengetahuan Alam. Universitas Negeri Semarang.

[13] Zainuri, dkk. 2010. "Analisa Pengaruh Variasi Merek Kampas Rem Tromol Sepeda Motor Honda Supra X125 Terhadap Keausan Kampas Rem”. Universitas Mataram.

[14] http://blog.unsri.ac.id/amir/material-teknik/pengujian-kekerasan-material/mrdetail/6808/

[15] http://komposit.co.id (21:04.3-11-2015)

[16] http://www.tpub.com/air/1-28.htm (22:15.7-11-2015)

[17] http://www.veterinaryonline.blogspot.com (22:15. 7-11-2015)

[18] http://Wikipedia.com/wikipediakomposit/2014 (23:45.7-11-2015)

[19] http://wahyujoko51117.blogspot.co.id/2013/03/kandungan-gizi-pada-tulang-dan.html （01:17.2-22016)

[20] http://blog.ub.ac.id/eka76/2012/05/30/keausan-dan-uji-keausan/ (02:31.2-2-2016) 